\title{
Emigración e exilio como tema na literatura dramática galega: algúns casos
}

\section{The Theme of Emigration and Exile in Galician Drama: Some Cases}

\author{
Roberto Pascual Rodríguez \\ Escola Superior de Arte Dramática de Galicia \\ robertopascual@edu.xunta.es
}

[recibido 29/10/2014, aceptado 26/01/2015]

Evan todos comedidos no paso, arrastrando o que deixan aqui. E ninguén fala. E ninguén fai nada. Tristes suben pola pasarela, e calados aceptan o seu destino.

(Roberto Salgueiro, Apnea)

\section{RESUMO}

Trazamos neste artigo un discurso analítico e comparativo a través dun percorrido pola literatura dramática galega onde o conflito da emigración se amosa como unha constante tráxica, dende as pezas de Antón Villar Ponte até as máis contemporáneas de Roberto Salgueiro, Cándido Pazó, Daniel Cortezón, etc.

PALABRAS CHAVE: Emigración, teatro galego, Irmandades da Fala, nova dramaturxia galega.

\section{RESUMEN}

Trazamos en este artículo un discurso analítico y comparativo a través de un recorrido por la literatura dramática gallega donde el conflicto de la emigración se muestra como una constante trágica, desde las piezas de Antón Villar Ponte hasta las más contemporáneas de Roberto Salgueiro, Cándido Pazó, Daniel Cortezón, etc.

PALABRAS CLAVE: Emigración, teatro gallego, Irmandades da Fala, nueva dramaturgia gallega.

\section{ABSTRACT}

In this article we draw an analytical and comparative discourse in Galician dramatic literature in which the conflict of emigration is seen as a tragic constant, from Anton Villar Ponte's works to those of Roberto Salgueiro, Cándido Pazó, Daniel Cortezón, etc.

KEY wORDS: Emigration, Galician theatre, Irmandades da Fala, new Galician dramaturgy.

Pascual Rodríguez, R. (2015): "Emigración e exilio como tema na literatura dramática galega: algúns casos", Madrygal (Madr.), 18, Núm. Especial: 291-297. 
Malia sermos un pobo de vagas migratorias en distintas épocas históricas e a diáspora formar parte da identidade e do capital simbólico da cultura galega, non son moitas as pezas teatrais que a teñan tratado como tema principal, aínda que si suficientes para analizarmos diacronicamente unha nómina destacábel, dende o teatro de tese até o de corte máis poético, dende a emigración americana até a europea.

Podemos situar como fito da creación dramática a abordaxe do mesmo no teatro Rexional Galego por parte de Ramón Armada Teijeiro no ano 1886 co apropósito líricodramático, con música de Feliciano do Rego e estrea precisamente alén mar, na Habana, baixo o título tan contundente coma expresivo de Non máis emigración. Pero interésanos ver a evolución no tratamento e as tendencias, algunhas dramaticamente inmutábeis, coma as grandes penurias cíclicas, deste tema da emigración ao longo da historia da nosa literatura dramática, que malia ser en palabras do propio Villar Ponte, outro dos dramaturgos que nos deixa mostra deste asunto, "un cancro esnaquizador das enerxías autóctonas" (Emilio Xosé Ínsua; Vilar Ponte 2002: 25), escaso tratamento tivo, sobre todo desvinculado do contexto rural e tamén por constituír un dos trazos de identidade do pobo galego en tanto conexións e experiencias interxeracionais relacionadas con algún familiar emigrante ou retornado, da que se derivan peripecias da máis frutífera e produtiva acción dramática, alén da didáctica ou política, á que non foi alleo o proxecto dramático das Irmandades da Fala, por exemplo.

En ningún caso, agás como primeiro paso para a liberación da opresión caciquil, transcende da trama protagonizada polo emigrante unha mensaxe positiva da emigración no corpus dramático galego analizado, pois como nos indica Emilio Xosé Ínsua a propósito de Almas Mortas, obra dramática de Vilar Ponte,

constátase facilmente como desde aquel posicionamento favorábel á emigración (en tanto mecanismo para fuxir dos abusos caciquís) expresado nos parlamentos polo personaxe "Vagamundo" n' A patria do labrego, o pensamento de Antón Villar Ponte tiña evoluído cara a unha visión abertamente crítica co papel "desgale- guizador" e zugador de enerxías que a emigración viña cumprindo na nosa sociedade. (Vilar Ponte 2002: 27)

Efectivamente, a condición de pobreza e peregrinaxe do simbólico "Vagamundo" n' $A$ patria do labrego contrasta coa submisión, o medo, o servilismo, a rutina e a escravitude inmoral do traballo coa que as clases baixas continúan a manter o poder e os abusos dos señoritos: "Deixar esta pátrea é tronzar as cadeas da escravitude e atopar a liberdade" (Vilar Ponte 2002: 82). O final aberto é unha estratexia dramática moi habitual en pezas do autor, non só nesta, senón tamén noutras coma Entre dous abismos en relación coa conveniencia da lexislación do divorcio. Así, n'A patria do labrego, o inmobilismo ou a frustración dese final aberto serve para que o espectador poida tirar as súas propias conclusións e a sociedade civil actúe dalgún xeito en relación á problemática da emigración e do mantemento ou continuidade do poder caciquil, xa que a ficción non avanza nese sentido.

Pola contra, na segunda obra, Almas mortas, a emigración é vista coma unha chegada de complexos, egoísmos e soberbias que derivan na castelanización da sociedade galega. Bota man Vilar Ponte de trazos ridicularizantes na caracterización dos personaxes, querendo retratar o estereotipo do "americano" a través, como indica o mesmo autor, dunha farsa patriótica. A resolución do conflito (o non poder marchar a inadaptada familia de Pancho por mor da súa enfermidade) vén dada pola tráxica morte deste, que subitamente nos precipita cara o final da peza mediante unha grotesca e simbólica acción, narrada polo médico da vila: "Parez unha morte simbólica... Foi pillado entre o carro cantareiro, primitivo e fermoso, encanto das nosas corredoiras, i-o automóvel exótico, que veu de América e se mercou con cartos da emigración. Agora, xa son libres, pra marcharen á súa terra" (Vilar Ponte 2002: 188).

$\mathrm{Na}$ precursora peza dramática líricomusical de Armada Teijeiro, que rebosa de emoción na súa sinxeleza estrutural da fábula e mesmo inocencia dende a nosa ollada contemporánea ao analizar o aparente motivo ou 
efecto desencadeante da fuxida do protagonista cara ao exilio (a presunta deshonra da amada, tema fatídico e de maior signo patriarcal da escena hispánica até o século XX), sitúa a Xan d'Os Picos, o protagonista, nun dos tópicos ligados non só ao sentimento do emigrante, senón tamén o da comunidade identificada entre si polo sentimento da saudade, do desacougo, do desasosego. O lance patético desta peza sitúase no segundo acto, cando enfermo no hospital, Xan d'Os Picos recibe a visita do seu amigo e rival na sombra Farruco, quen se confesa artífice de argallar as sospeitas para a súa fuxida e así deixar vía libre á relación coa desputada amada Marica. Ante a confesión e a lectura das cartas da nai e da amada, Xan vese obrigado a retornar con urxencia para evitar tamén o crecemento da enfermidade en ambas, enfermidade da saudade e do desapego que a inmisericorde man da emigración provoca nas dúas bandas, a que marcha (normalmente a masculina) e a que fica (a feminina) pois certo é que nunha gran maioría das pezas analizadas este rol non só é unha constatación senón tamén un motivo aparición de novos conflitos: o home que crea nova familia na diáspora, o que procura o recoñecemento e as honras na presunta filantropía do retorno ao lugar natal, etc.

Mais volvendo á situación da imposibilidade de retornar ao non ter saúde nin cartos para poder facelo e sentir a carta coma unha ferinte imposibilidade, como unha borralla da brasa que se apaga sen poder facer nada, o protagonista de Non máis emigración matina no suicidio como única saída ao seu desespero. Pero coma nas comedias áureas do Século de Ouro, a través dun áxil procedemento "deus ex machina", unha personificación simbólica que di ser a Sociedade de Beneficencia Gallega da Habana, coma unha alegoría á solidariedade e ás bondades da nación galega que coida dos seus fillos polo inhóspito mundo, sálvao de tal traxedia e retorna en ledica o final do drama. Desta trama subxacen dous asuntos importantes. Un deles é a exaltación dunha institución que en realidade se fundou no ano 1871 nos salóns do Teatro Albisu e levou a cabo meritorias labores de acción social e difusión cultural. Baste lembrar que baixo a advocación da Sociedad de Beneficencia de Naturales de Galicia fundarase o Centro Gallego da Habana. Pero o segundo asunto subxacente, derivado do primeiro e quizais máis relevante, é a idea de frustración que xeran os esforzos e o sacrificio da emigración que atopa tanta ou máis miseria coma na terra de partida, peores condicións laborais ou peor calidade de vida e de relacións interpersoais.

O anceio do retorno, de voltar ás raíces, é unha constante que atopamos tamén en varias obras. Vémolo no obxectivo da personaxe feminina de Ida e Volta, de Xosé Manuel Pazos (obra escrita para o espectáculo "Emigrados" de Teatro de Ningures e que xunto a outras tres pezas breves máis obtivo en 2008 o Premio Max ao mellor texto teatral en lingua galega) e tamén na parella protagonista de Exiliados, obra de Jenaro Marinhas del Valle (1986). Concretamente nesta segunda, Bieito, o membro masculino da parella afirma: "Seremos o un para o outro alá, na nosa terra que nos parece a mellor terra do mundo apesares da súa pobreza, do seu atraso, do seu abandono de si e, o máis pior, da resignación suicida da súa xente" (Marinhas del Valle 2006: 248). Nesta diagnose, que tamén comparte a personaxe da "Boneca do XVIII francés, preciosa e esbranquecida", de Apnea, de Roberto Salgueiro, que se cita no comezo deste artigo, radica o paradoxo de querer volver, feito reparador e positivo nalgún caso e tráxico ou truncado na súa consecución case inmediata noutros. $\mathrm{Na}$ obra de Marinhas del Valle a imposibilidade vén dada por un inesperado accidente do protagonista que, nun final aberto, non nos desvelará se falece ou non. Pero as consecuencias teñen repercusión tamén nunha amiga da parella, namorada do propio Bieito, Selena, quen suma á súa traxedia persoal de non ser aceptada pola súa familia (coma unha condena ao non retorno, ao repudio) a crise da situación á que responde co suicidio do corpo indemne e da alma esnaquizada, como ela mesma di, regresando ao lupanar, a exercer a prostitución.

A emigración europea é tratada con gran ollada e multiperspectiva na dramaturxia galega 
contemporánea pola peza paisaxe ${ }^{1}$, onde $\mathrm{o}$ conflito íntimo e familiar tamén se converte en drama colectivo, Historia da chuvia que cae todos os dias, de Roberto Salgueiro. Tamén na comedia ou monólogo con incisións de elementos audiovisuais titulado Cochos, de Roberto Vidal Bolaño. A propósito da primeira, protagonizada por un adolescente castigado pola lacra do desemprego e ao mesmo tempo defensor dos débiles, fronte á receita do espírito aventureiro dos actuais responsábeis de gabinetes ministeriais, amósanos, como diciamos noutra ocasión (Pascual Rodríguez 2008: 42):

A outra cara da emigración, a europea, noutra xeración, a do pai. Emigrante suízo retornado que, nun primeiro momento, se nos presenta como un personaxe cuxa experiencia pretende ser a verdade absoluta, desdeñando calquera avance ou reforma que a xente nova, coma o seu fillo, pretenda levar a cabo. (...) Remoído pola dureza do seu propio existir, Manuel, o pai, é quen de amosar desculpa e humilde xustificación in extremis, conseguindo que a calor do seu fogar depoña a idea de marchar para Lanzarote: “... fun un cabrón. Pero non quero que agora estragues o que tes. Que vas facer aló? Este é o teu lugar, Andrés. Aquí tes a túa vida".

Consello sincero e alentador dun pai que pide valentía e aguante a quen loita por vivir dignamente, con todos os atrancos, na súa terra? Egoísmo ante a posibilidade de verse só tras a marcha do fillo? Pánico a rememorar os duros anos da separación e da emigración? A nada disto nos responde a peza e a todos estes matices e ambigüidades se debe achegar o lector-espectador coma nas mellores obras, onde o conflito latexa mais pouco se conclúe, coma na vida dos máis desfavorecidos, neste caso dos castigados pola dolorosa emigración que rompe os lazos dos afectos e os vínculos do amor.
Unha das obras máis irónicas e que trata dun xeito máis cru e traxicómico a cuestión da emigración europea é Cochos, de Vidal Bolaño. A traxedia radica na incomprensión, na sobrepasada dimensión que cobra unha rareza como é que un emigrante galego en Alemaña viva nun barracón cunha porca e iso supoña unha ameza para a saúde e a seguridade do estado máis ca na consecuencia diso mesmo. A consecuencia será o suicidio do protagonista, Sebas Rilo, que ante o asedio e o despregamento das forzas do estado, dos medios de comunicación, do consulado e da intervención telefónica da súa propia muller, acaba por dirixirse á súa porca para despedirlle e encomendarlle, coma se el fose tamén un porco, o posterior tratamento do seu sangue, tripas, frebas, untos e demais restos corporais. Loucura? Situación grotesca e granguiñolista tan do gusto deste renovador da escena contemporánea galega nos 70 e 80 ? Retrato da miseria e da ignorancia ou da bonhomía e da inocencia dun home que leva un porco como reflexo da súa condición e da única conexión co fogar natal e como contribución ao aforro do emigrante? Ben é sabido o que supón o porco para a economía galega de moitos fogares rurais da $\mathrm{Ga}-$ licia daquela época e do valor deste membro no fogar, que chegado o momento se mata sen reparo para nutrir a familia case dun xeito caníbal. E impedilo, como pretenden, entrando pola forza no inmundo barracón do Sebas, é case coma un atentado á idiosincrasia do feito e da dignidade dese galego que instala un anaco da súa Galicia (mesmo miserenta se queremos) na inmundicia dos barracóns para emigrantes na poderosa e avanzada Alemaña.

Tamén para Alemaña marchan os fillos dos dous protagonistas da peza A diáspora (1981), do dramaturgo Daniel Cortezón. Dous vellos ancorados no rural minifundista, inmobilista, ven como progresivamente os seus descendentes foxen cara un dos países europeos

\footnotetext{
${ }^{1}$ Referímonos, co termo "peza paisaxe", a aquelas obras que nos presentan o retrato dun ambiente con certa profundidade e que, como consecuencia, non queda no íntimo, nos conflitos entre personaxes. A peza paisaxe amósanos as consecuencias das condicións físicas e a súa relación indisoluble coa posición anímica e coa conduta das persoas e forzas que a habitan. A materialidade das escenas, os significantes, son unha parte indisoluble da identidade dese universo creativo.
} 
industrializados que máis emigración galega acolleu no último terzo do século XX. $\mathrm{O}$ vello é, aparentemente, gran defensor da emigración, quizais pola experiencia positiva que disque supuxo para a súa xeración e irmáns que emigraron a Cuba, Arxentina, Brasil e Venezuela e alí fixeron riqueza. A nai, pola contra, sente unha dor e unha saudade que axiña recoñecerá ante a aparición máxica do personaxe do cego como doenza psíquica (e que propiciará un efecto de anagnórise na personaxe, coma no teatro clásico grego), motivada pola perda dos fillos e o progreso no seu fogar.

A peza contén trazos do teatro farsesco medieval, do teatro clásico (o coro) e do teatro popular, mesmo cantigas de cego, personaxe simbólico que aparece para encirrar, molestar ou amargar a festa na romaría dun verán de reencontro familiar. Se a festa funciona como sedante e anestesia da dor que seguramente o vello tamén padeza pero que non evidencia nin recoñece, o cego é esa imaxe que informa, que molesta, remexe e incita a que as cousas non permanezan estancadas con sedimentos de máis silencio resignación. Como sempre foi este comediante da legua ao longo da historia do teatro, ás veces cumpre dende a función xornalística de informar e fomentar o pensamento crítico arredor dun suceso até a de provocar a través do esaxero, o ruído, a deturpación con intención impactante e a propia estratexia de venda dos seus cordeis. Vexamos, por exemplo, o relato da emigración que realiza o cego a partir dun suceso tráxico coma o suicidio (Cortezón 1981: 69-71):

Polo camiño de Francia polo camiño amargo no tren de ferro e madeira os emigrantes marchando.

Señoras e señores vexan donas e cabaleiros de rango e os probes galegos nuos inspeución médica agardando.

Póñenos en coiros vivos en coiros vivos tremando pra que os doutores digan si están bos pró [traballo.

Dista sorte os admiten nas fábricas certificando, outros pra ceifálo trigo outros pra vendimar chorando.

As mulleres foron postas nos barracós daquil campo, regatos polo meio corren alí os nenos criando.

Bágoas as mulleres choran pro temen e van calando, pois botarlos do país queren que agora van estorbando.

Así nistros sofrimentos os anos foron pasando, os probes galegos aforran e mandan os cartos aos Bancos.

Polo camiño de Francia os emigrantes voltando, algún diñeiro aforraron sangue e suor xorrando.

O diñeiro lles devolven que xa non vale un carto, ninguén esprica óndia foron o sangue e suor botando.

«De ouro e sangue fundidos de sangue e ouro ganados metín a vida nun Banco e agora devólvenme un ano».

E Xan dos Mingos berrando tresleado e sin razón colleu o coitelo dos porcos e tolo se foi suicidando.

Diste xeito miñas donas, señores de condición, morren de probes ou tolos os Cristos da emigración. (INTENCIONALMENTE, NA IDEA DE FACER MÁIS GROTESCA E FERINTE A ESCEA, APRAUSOS DE TODOS. O CEGO SAÚDA)

Pero non podemos deixar pasar o outro cantar que se insire no drama de Cortezón por todo canto posúe de chamada revolucionaria e arenga colectiva de todos os compatriotas da emigración galega polo fin da paciencia e a chamada ao comezo do empoderamento da sociedade galega no seu territorio, dende os principios da igualdade e da posta en valor do capital humano e material (Cortezón 1981: 75-76): 
Sobor dos lombos vilaos e labregos aa fame

[da terra,

emigrante galego, mohinante do mundo,

ti conoces as brilantes estrelas de ourente

e o azur roteiro do mar das Américas;

emigrante galego,

compañeiro.

Sin retorno te fuche i espallache teus osos, emigrante galego, sal e tona da terra, e $\sin$ berros deixache os eidos famentos pra murchar doorido nas patrias alleas; emigrante galego,

compañeiro.

Ti deixaches valeiros as áiras e adros, pra que foran comestos das panzas burguesas, dos vermes parásitos que non falan tua fala, samesugas tredoras, funcioarios mercados; emigrante galego,

compañeiro.

Ti limpache de sempre o estrume dos ricos rompendo os brazos nos traballos peores, ceifando escravo as alleas colleitas e na proletaria agonía sulagado; emigrante galego, compañeiro.

Ti fas moradía nas cachoupas infectas mentres ergues ás nubens os andamios do

constructor ilota das torres luxosas [ferro,

dos novos señores de forca e barazo; emigrante galego,

compañeiro.

Choraron por séculos as mulleres de loito e os fillos orfos encheron os pobos, mentras cos ollos abertos no eterno asoro fuxen tamén da fame da terra; emigrante

compañeiro.

[galego,

Pro os tempos rematan, o mencer se aproxima, unha leda mañán aloumiña a Galiza, badaladas de bronce abraguen o áer anunciando a todos o fin da paciencia: emigrante galego, ¡Irmandiño!

Obsérvese o uso da epínome "emigrante galego, compañeiro", que no derradeiro verso muda pola admirativa "emigrante galego, ¡Irmandiño!", co derivado cambio da función expresiva, que apela á forza heroica da revolta medieval para conectala coas situacións contemporáneas de novas inxustizas e abusos.

Igualmente, co elocuente título de Dúas mamás, Cándido Pazó preséntanos na súa composición dramatúrxica un encontro entre dúas mulleres tocadas pola emigración. Unha delas co recordo da infancia da emigración europea de seus pais e outra, no tempo presente da ficción, asistenta do fogar que a raíz de quedar durmida atendendo á nai da primeira mantén unha desveladora conversa arredor da idea de fracaso, necesidade ou desgarro que supón a separación entre pais e fillos por mor da emigración.

Da trama subxace unha dupla visión: a da filla, que adulta recorda aquela circunstancia de ficar coa avoa (a súa outra mamá) e visitar nas vacacións aos pais emigrados en París, cidade que nunca coñecerá até ir de turista, malia viviren alí seus pais que, por descoido, precariedade da familia emigrada ou desatención coa filla visitante, nunca lle amosarán o París das estampas turísticas. Por outra banda, ante a sinceridade da confesión daquela, a muller coidadora sofre, a través dese relato que provoca unha mise en abyme, un recoñecemento do lado da nai que deixou no seu país natal á súa filla para traballar arreo e na precariedade, pluriempregada nun bar e como asistenta a domicilio, pero susceptíbel tamén á perda do cariño e do agarimo da súa filla co paso do tempo. A través desta circunstancia exposta de xeito cíclico, a emigración preséntase como unha necesidade pero tamén coma unha traxedia de lentas e inapreciábeis consecuencias, coma un dobre castigo de precariedade en terra allea e de ruptura de vínculos familiares e/ ou afectivos co lugar de orixe.

Botamos de menos unha visión dende a dramaturxia dunha parte importante da emigración galega, a do exilio político, aquela que tanto marcou a historia da galeguidade no exterior durante o franquismo e que nas letras dramáticas do estado está a ser tan ben tratada, por exemplo en pezas coma $E l$ barbero de Picasso, de Borja Ortiz de Gondra. Aquela dramaturxia, en fin, que nos faga sentir tamén a través da acción dramática a outra dor da partida, a do capital humano que abandona 
unha terra por mor da falta de liberdade. A carencia da igualdade de oportunidades tivo en distintas épocas a súa manifestación dramática, como vimos, a través dun estrato marxinal moitas veces no destino e no retorno, cargado de culpas ás veces e de remorsos, de soños e frustracións, en todo caso ben lonxe dese espírito aventureiro co que hoxe algúns pretenden convencer a novas xeracións para que se decidan a abandonar (se cadra forzosamente) o seu país natal. Agardamos que o teatro tamén nos presente a súa visión desta situación, pois esa tamén sempre foi a función social desta arte, facernos tomar perspectiva con respecto ás problemáticas do presente (que en moitos casos tamén son do pasado).

\section{REFERENCIAS BIBLIOGRÁFICAS}

Cortezón, Daniel (1981): A diáspora. Sada: Ediciós do Castro.

Marinhas del VAlle, Jenaro (2006): Obra dramática completa. Culleredo: Espiral Maior.

PASCUAl Rodríguez, Roberto (2008): “Auxe do neorrealismo dramático”, Grial. Revista galega de cultura 179 , pp. 117-118.

PAzó, Cándido (2008): Dúas mamás. Revista Galega de Teatro 57 (Textos 54), pp. 5-15.

SAlgueIro, Roberto (2008): Historia da chuvia que cae todos os días. Vigo: Xerais.

Vidal Bolaño, Roberto (1992): Cochos. Santiago de Compostela: Sotelo Blanco.

Vilar Ponte, Antón (2002): A patria do labrego. Almas mortas. A Coruña: La Voz de Galicia. 